\title{
AVALIAÇÃO DE MÉTODOS INDIRETOS DE DETERMINAÇÃO DA ERODIBILIDADE DE LATOSSOLOS BRASILEIROS ${ }^{1}$
}

\author{
MARX LEANDRO NAVES SILVA² ${ }^{2}$ NILTON CURI², JOSÉ MARIA DE LIMA² e MOZART MARTINS FERREIRA²
}

\begin{abstract}
RESUMO - Existem três maneiras de se determinar a erodibilidade do solo (Fator K). A primeira envolve a determinação do fator $\mathrm{K}$ em condições de campo, sob chuva natural, a qual é onerosa e muito demorada. O segundo método é semelhante ao primeiro, porém baseia-se na quantificação do fator $\mathrm{K}$ em razão das perdas de solo e do fator erosividade, sob condições de chuva simulada. O terceiro método baseia-se em regressões múltiplas que contenham, como variáveis independentes, atributos do solo correlacionados com o fator K obtido pelos dois métodos anteriores, tidos como padrões. A carência de dados básicos e a indefinição do melhor método para determinação da erodibilidade de maneira indireta, que possibilite enquadrar os solos em classes de resistência à erosão, constituem problemas na utilização destes métodos indiretos, particularmente nos Latossolos brasileiros. Portanto, objetivou-se com este estudo a determinação indireta da erodibilidade desses solos e avaliação da correlação com os métodos diretos. Nenhum dos métodos testados mostrou-se recomendável para a estimativa da erodibilidade para o conjunto de Latossolos do Brasil, sendo necessário, então, desenvolver modelos específicos para este grupamento de solos.
\end{abstract}

Termos para indexação: erosão, deterioração do solo, análise de solo, métodos analíticos.

\section{EVALUATION OF INDIRECT METHODS FOR DETERMINATION OF ERODIBILITY OF BRAZILIAN LATOSOLS (OXISOLS)}

\begin{abstract}
There are three ways for determining the soil erodibility (K-factor). The first one includes the $\mathrm{K}$-factor determination at field conditions, under natural rainfall, which is expensive and time consuming. The second method is similar to the first one, but it is based upon the quantification of $\mathrm{K}$-factor as a function of soil losses and the erosivity factor, under simulated rainfall. The third method is based upon multiple regressions which include as independent variables soil attributes correlated with the K-factor obtained by the two former methods, considered as standards. The lack of basic data and the indefinition of the best method for the determination of the indirectly determined erodibility, which would allow to frame the soils into erosion resistance classes, constitute problems in the utilization of these indirect methods, particularly for the Brazilian Latosols (Oxisols). Therefore, this study aimed to determine the erodibility of these soils by indirect methods and the evaluation of the correlation between these methods and the direct ones. None of the tested methods allowed good estimation of erodibility for the set of Latosols of Brazil, being necessary the development of specific models for this group of soils.
\end{abstract}

Index terms: erosion, soil deterioration, soil analysis, analytical methods.

\section{INTRODUÇÃO}

A erodibilidade do solo representa o efeito integrado dos processos que regulam a infiltração de

${ }^{1}$ Aceito para publicação em 22 de junho de 1999.

Extraído da tese de doutorado apresentada pelo primeiro autor à Universidade Federal de Lavras, MG. Trabalho apresentado no XXVI Congresso Brasileiro de Ciência do Solo, Rio de Janeiro, RJ, 20 a 26 de julho de 1997.

${ }^{2}$ Eng. Agrôn., PhD., Dep. de Ciência do Solo, Universidade Federal de Lavras (UFLA), Caixa Postal 37, CEP 37200-000 Lavras, MG. E-mail: marx@ufla.br água e a resistência do solo à desagregação e transporte de partículas (Lal, 1988); portanto, refere-se à sua predisposição à erosão. E o fator que tem despertado o maior interesse na pesquisa de erosão, por ser governado pelos atributos intrínsecos do solo, os quais podem variar de solo para solo e com o tipo de manejo.

Basicamente, existem três maneiras diferentes de se determinar a erodibilidade do solo. A primeira envolve a determinação do fator $\mathrm{K}$ em condições de campo, sob chuva natural; entretanto, este método é oneroso e muito demorado. O segundo método é 
semelhante ao primeiro, porém baseia-se na quantificação do fator $\mathrm{K}$ em razão das perdas de solo e do fator erosividade, sob condições de chuva simulada. Estes dois métodos são considerados padrões e refletem a erodibilidade do solo como é preconizada pela Equação Universal de Perdas de Solo (EUPS) (Wischmeier \& Smith, 1978). O terceiro método baseia-se em regressões múltiplas que contenham como variáveis independentes atributos morfológicos, físicos, químicos e mineralógicos do solo ou relações destes, correlacionados com o fator $\mathrm{K}$ obtido pelos métodos padrões.

Na literatura existe uma série de métodos propostos e adaptações destes para a determinação da erodibilidade do solo em vários países, como: Tunísia (Dumas, 1965), EUA (Middleton, 1930; Wischmeier \& Mannering 1969; Wischmeier et al., 1971; Roth et al., 1974; El-Swaify \& Dangler, 1977; Römkens et al., 1977; Young \& Mutchler, 1977), Venezuela (Paez, 1989) e Brasil (Lombardi Neto \& Bertoni, 1975; Denardin, 1990; Lima et al., 1990; Chaves, 1994; Roloff \& Denardin, 1994, citados por Silva, 1997; Marques et al., 1997).

A carência de dados básicos e a indefinição do melhor método para determinação da erodibilidade de maneira indireta, que possibilite enquadrar os Latossolos brasileiros em classes de resistência à erosão, constituem problemas na utilização da EUPS, na avaliação da qualidade do solo em relação à erosão hídrica e na elaboração de estratégias de desenvolvimento de uso do solo de forma sustentada. Diante do exposto, este estudo teve por objetivo a determinação indireta dos índices de erodibilidade desses solos e avaliação da correlação destes com índices padrões obtidos de maneira direta com coletores de chuva natural ou com simuladores de chuva.

\section{MATERIAL E MÉTODOS}

Foram obtidas amostras do horizonte A de Latossolos (Tabela 1) das várias regiões geográficas do Brasil, cuja erodibilidade tinha sido determinada por métodos diretos, ou seja, em parcelas experimentais sob chuva natural ou com simulador de chuva.

A análise granulométrica dos solos foi realizada pelo método da pipeta (Day, 1965), empregando-se $\mathrm{NaOH} 0,1 \mathrm{~mol} \mathrm{~L}^{-1}$ como dispersante químico, e agitação rápida $(12.000 \mathrm{rpm})$ durante 10 minutos. $\mathrm{O}$ fracionamento da terra fina em água também foi realizado pelo método da pipeta, sendo que as frações com partículas e/ou agregados maiores que $0,1 \mathrm{~mm}$ foram separadas por peneiramento (peneira de $0,105 \mathrm{~mm}$ ), e as frações de tamanho menor, por sedimentação, segundo a lei de Stokes. A fração areia $(2,0$ a $0,053 \mathrm{~mm})$ foi subdividida em cinco classes: areia muito grossa (2,0 a $1,0 \mathrm{~mm})$, areia grossa $(1,0$ a $0,5 \mathrm{~mm})$, areia média $(0,5$ a $0,25 \mathrm{~mm})$, areia fina $(0,25$ a $0,105 \mathrm{~mm}) \mathrm{e}$ areia muito fina $(0,105$ a $0,053 \mathrm{~mm})$. Além destas foi separada e quantificada a porcentagem de calhaus (partículas entre 2,0 e $20,0 \mathrm{~cm}$ )

As classes de estrutura e permeabilidade foram codificadas de acordo com Wischmeier et al. (1971), com base na descrição geral do perfil dos solos e na descrição morfológica do horizonte A. Assim, a estrutura foi codificada em: muito pequena granular $=1$; pequena granular $=2$; média a grande granular $=3$; blocos, laminar ou maciça $=4$. A permeabilidade foi codificada em: rápida $=1 ;$ moderada a rápida $=2 ;$ moderada $=3$; lenta a moderada $=4 ;$ lenta $=5$. A umidade equivalente foi determinada conforme metodologia da Embrapa (1979)

A estabilidade de agregados foi determinada por meio de tamisação em água, após pré-umedecimento lento, segundo Oliveira et al. (1983) e Kemper \& Rosenau (1986). A partir desta análise foi determinada a proporção de agregados menores que $0,25 \mathrm{~mm}$, também chamada de índice de instabilidade, segundo El-Swaify \& Dangler (1977).

Foram feitas análises do complexo sortivo, $\mathrm{pH}$ (em água e em $\mathrm{KCl} 1 \mathrm{~mol} \mathrm{~L}^{-1}$ ), óxidos $\left(\mathrm{SiO}_{2}, \mathrm{Al}_{2} \mathrm{O}_{3}\right.$ e $\left.\mathrm{Fe}_{2} \mathrm{O}_{3}\right)$ extraídos pelo ataque sulfúrico e carbono orgânico (Embrapa, 1979). Também foram feitas determinações de $\mathrm{SiO}_{2}, \mathrm{Al}_{2} \mathrm{O}_{3}$ e $\mathrm{Fe}_{2} \mathrm{O}_{3}$ extraídos pelo ditionito-citrato-bicarbonato de sódio (DCB), na fração argila, segundo Mehra \& Jackson (1960). A determinação de $\mathrm{Fe}_{2} \mathrm{O}_{3}$ (DCB) foi feita por absorção atômica. $\mathrm{O} \mathrm{Al}_{2} \mathrm{O}_{3}$ (DCB) foi determinado por colorimetria, pelo método do aluminon (McKeague, 1978), sendo a eliminação do citrato obtida através da combinação dos métodos de McKeague (1978) e Camargo et al. (1986). A determinação de $\mathrm{SiO}_{2}$ (DCB) foi feita por colorimetria, segundo Weaver et al. (1968). Todos os valores determinados na fração argila foram corrigidos para a TFSE (terra fina seca em estufa) e todas as análises foram feitas com quatro repetições.

Foram testados 23 modelos indiretos de estimativa da erodibilidade (fator $\mathrm{K}$ ), expressos em $\mathrm{th}(\mathrm{MJ} \mathrm{mm})^{-1}$. As equações utilizadas foram as seguintes: (I), (II), (III), (IV) e (V) modelos para solos da Tunísia desenvolvidos por Dumas (1965); (VI) modelo desenvolvido para a região do Meio-Oeste dos EUA por Wischmeier et al. (1971); (VII) modelo para subsolos argilosos dos EUA desenvolvido 
TABELA 1. Classificação, meio físico e erodibilidade obtida de maneira direta, nos solos estudados.

\begin{tabular}{|c|c|c|c|c|c|c|c|c|}
\hline \multirow{2}{*}{$\begin{array}{c}\text { Solo } \\
\left(\mathrm{n}^{0}\right)\end{array}$} & \multirow[t]{2}{*}{ Classificação } & \multirow[t]{2}{*}{ Localização } & \multicolumn{2}{|c|}{ Coordenadas } & \multirow{2}{*}{$\begin{array}{l}\text { Altitude } \\
(\mathrm{m})\end{array}$} & \multirow{2}{*}{$\begin{array}{c}\text { Clima } \\
\text { (Köppen) }\end{array}$} & \multirow{2}{*}{$\begin{array}{l}\text { Erodibilidade } \\
\left(\mathrm{t} \mathrm{h} \mathrm{M{ } ^ { - 1 }} \mathrm{mm}^{-1}\right)\end{array}$} & \multirow[t]{2}{*}{ Fonte } \\
\hline & & & Lat. & Long. & & & & \\
\hline 1 & $\begin{array}{l}\text { Latossolo Roxo distrófico, textura argilosa, fase } \\
\text { floresta subtropical, relevo ondulado }\end{array}$ & Ijuí, RS & $28^{\circ} 23^{\prime} \mathrm{S}$ & $53^{\circ} 54^{\prime} \mathrm{W}$ & 448,0 & $\mathrm{Cfa}$ & $0,009(\mathrm{CN})^{1}$ & Denardin (1990) \\
\hline 2 & $\begin{array}{l}\text { LatossoloVermelho-Escuro distrófico, textura } \\
\text { argilosa, fase floresta subtropical, relevo ondulado }\end{array}$ & Passo Fundo, RS & $28^{\circ} 15^{\prime} \mathrm{S}$ & $52^{\circ} 24^{\prime} \mathrm{W}$ & 709,0 & $\mathrm{Cfa}$ & $0,021(\mathrm{CN})$ & Denardin (1990) \\
\hline 3 & $\begin{array}{l}\text { Latossolo Roxo distrófico, textura argilosa, fase } \\
\text { floresta subtropical alta, mista, com araucárias, } \\
\text { relevo ondulado e suave ondulado }\end{array}$ & Chapecó, SC & $27^{\circ} 6^{\prime} \mathrm{S}$ & $52^{\circ} 40^{\prime} \mathrm{W}$ & 700,0 & $\mathrm{Cfa}$ & $0,016(\mathrm{CN})$ & Silva (1997) \\
\hline 4 & $\begin{array}{l}\text { Latossolo Vermelho-Escuro distrófico, textura } \\
\text { argilosa, fase floresta tropical perenifólia, relevo } \\
\text { suave ondulado }\end{array}$ & Ponta Grossa, PR & $25^{\circ} 6^{\prime} \mathrm{S}$ & $50^{\circ} 10^{\prime} \mathrm{W}$ & 868,5 & $\mathrm{Cfb}$ & $0,022(\mathrm{CN})$ & Angulo (1983) \\
\hline 5 & $\begin{array}{l}\text { Latossolo Roxo eutrófico, textura argilosa, fase } \\
\text { floresta tropical subperenifólia }\end{array}$ & Londrina, PR & $23^{\circ} 19^{\prime} \mathrm{S}$ & $51^{\circ} 19^{\prime} \mathrm{W}$ & 566,0 & $\mathrm{Cfa}$ & $0,025(\mathrm{CS})^{2}$ & Mondardo et al. (1978) \\
\hline 6 & $\begin{array}{l}\text { Latossolo Vermelho-Escuro álico, textura média, } \\
\text { fase floresta tropical subperenifólia, relevo plano a } \\
\text { suave ondulado }\end{array}$ & Paranavaí, PR & $23^{\circ} 5^{\prime} \mathrm{S}$ & $52^{\circ} 26^{\prime} \mathrm{W}$ & 480,0 & $\mathrm{Cfa}$ & $0,008(\mathrm{CS})$ & Angulo (1983) \\
\hline 7 & $\begin{array}{l}\text { Latossolo Vermelho-Escuro distrófico, textura } \\
\text { média, fase floresta tropical subperenifólia, relevo } \\
\text { suave ondulado }\end{array}$ & $\begin{array}{l}\text { Bela Vista do } \\
\text { Paraíso, PR }\end{array}$ & $22^{\circ} 57^{\prime} \mathrm{S}$ & $51^{\circ} 12^{\prime} \mathrm{W}$ & 600,0 & $\mathrm{Cfa}$ & $0,026(\mathrm{CN})$ & Angulo (1983) \\
\hline 8 & $\begin{array}{l}\text { Latossolo Roxo distrófico, textura muito argilosa, } \\
\text { fase floresta tropical subcaducifólia, relevo suave } \\
\text { ondulado }\end{array}$ & Campinas, SP & $22^{\circ} 54^{\prime} \mathrm{S}$ & $47^{\circ} 5^{\prime} \mathrm{W}$ & 669,0 & Cwa & $0,012(\mathrm{CN})$ & $\begin{array}{l}\text { Bertoni \& Lombardi Neto } \\
\text { (1985) }\end{array}$ \\
\hline 9 & $\begin{array}{l}\text { Latossolo Roxo eutrófico, textura muito argilosa, } \\
\text { fase floresta subperenifólia }\end{array}$ & Dourados, MS & $22^{\circ} 14^{\prime} \mathrm{S}$ & $54^{\circ} 59^{\prime} \mathrm{W}$ & 454,0 & Cfa & $0,004(\mathrm{CN})$ & Hernani et al. (1997) \\
\hline 10 & $\begin{array}{l}\text { Latossolo Vermelho-Escuro distrófico, textura } \\
\text { argilosa, fase floresta latifoliada tropical, relevo } \\
\text { ondulado }\end{array}$ & Jaboticabal, SP & $21^{\circ} 15^{\prime} \mathrm{S}$ & $48^{\circ} 18^{\prime} \mathrm{W}$ & 595,0 & Cwa & $0,009(\mathrm{CS})$ & $\begin{array}{l}\text { Martins Filho \& Pereira } \\
\text { (1993) }\end{array}$ \\
\hline 11 & $\begin{array}{l}\text { Latossolo Vermelho-Escuro distrófico, textura } \\
\text { muito argilosa, fase cerrado, relevo suave ondulado }\end{array}$ & Lavras, MG & $21^{\circ} 5^{\prime} \mathrm{S}$ & $45^{\circ} 0^{\prime} \mathrm{W}$ & 910,0 & $\mathrm{Cw}$ & $0,004(\mathrm{CS})$ & Silva et al. (1994a) \\
\hline 12 & $\begin{array}{l}\text { Latossolo Vermelho-Amarelo distrófico, textura } \\
\text { muito argilosa, fase cerrado, relevo suave ondulado }\end{array}$ & Lavras, MG & $21^{\circ} 5^{\prime} \mathrm{S}$ & $45^{\circ} 0^{\prime} \mathrm{W}$ & 935,0 & $\mathrm{Cw}$ & 0,010 (CS) & Silva et al. (1994a) \\
\hline 13 & $\begin{array}{l}\text { Latossolo Vermelho-Escuro álico, textura muito } \\
\text { argilosa, fase cerrado tropical subcaducifólio, relevo } \\
\text { suave ondulado }\end{array}$ & Sete Lagoas, MG & $19^{\circ} 25^{\prime} \mathrm{S}$ & $44^{\circ} 15^{\prime} \mathrm{W}$ & 732,0 & Aw & $0,002(\mathrm{CN})$ & Marques et al. (1997) \\
\hline 14 & $\begin{array}{l}\text { Latossolo Vermelho-Escuro distrófico, textura } \\
\text { argilosa, fase cerrado tropical subcaducifólio, relevo } \\
\text { suave ondulado }\end{array}$ & Goiânia, GO & $16^{\circ} 41^{\prime} \mathrm{S}$ & $49^{\circ} 23^{\prime} \mathrm{W}$ & 729,5 & Aw & $0,009(\mathrm{CN})$ & Silva et al. (1997) \\
\hline
\end{tabular}




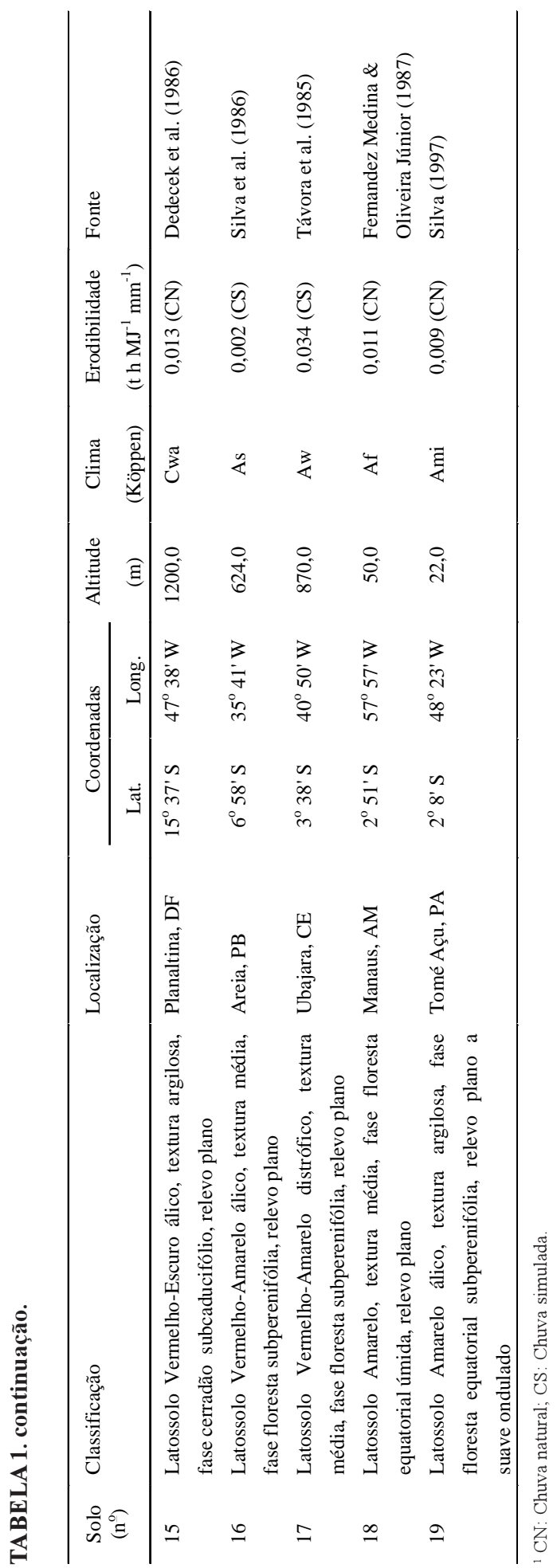

por Roth et al. (1974); (VIII) relação de erosão proposta por Lombardi Neto \& Bertoni (1975), com base em Middleton (1930); (IX) e (X) modelos desenvolvidos para solos do Havaí (EUA) por El-Swaify \& Dangler (1977); (XI), (XII) e (XIII) modelos desenvolvidos para subsolos argilosos dos EUA por Römkens et al. (1977); (XIV) modelo para solos da Venezuela desenvolvido por Paez (1989); (XV) relação de erosão proposta por Lombardi Neto \& Bertoni (1975), modificada por Lima et al. (1990); (XVI) adaptação do método anterior para Latossolos brasileiros proposta por Lima et al. (1990); (XVII) e (XVIII) modelos para solos do Brasil propostos por Denardin (1990); (XIX) e (XX) modelos para solos do Estado do Paraná propostos por Roloff \& Denardin (1994), citados por Silva (1997); (XXI) modelo para Latossolos (horizonte Bw) e Areias Quartzosas do Estado do Paraná proposto por Roloff \& Denardin (1994), citados por Silva (1997); (XXII) modelo para solos Podzólicos e Terra Roxa Estruturada (horizonte Bt) do Estado do Paraná, proposto por Roloff \& Denardin (1994), citados por Silva (1997); (XXIII) modelo desenvolvido para os solos da região do Vale do Rio São Francisco, por Chaves (1994).

Os modelos foram ajustados para que a erodibilidade fosse expressa no Sistema Internacional de Unidades, segundo Foster et al. (1981). Para a comparação dos métodos (diretos x indiretos), foram feitas correlações de Pearson entre os valores de $\mathrm{K}$ medidos no campo ( $\mathrm{K}$ observado) e os avaliados pelos diferentes métodos indiretos ( $\mathrm{K}$ estimado). Essas correlações foram testadas quanto à sua significância pelo teste t a $5 \%$ de probabilidade.

\section{RESULTADOS E DISCUSSÃO}

Os valores de erodibilidade obtidos pelo método direto (Tabela 1) apresentaram uma amplitude de 0,002 a $0,034 \mathrm{th}(\mathrm{MJ} \mathrm{mm})^{-1}$. Estes resultados estão de acordo com os encontrados na literatura por El-Swaify \& Dangler (1992) em Oxissolos de região tropical.

Nas Tabelas 2 a 4 são apresentados os parâmetros utilizados nos 23 modelos indiretos de estimativa da erodibilidade. As relações entre os índices de erodibilidade obtidos pelos métodos diretos e os obtidos pelos vários modelos são apresentadas nas Figs. 1 a 4. Observa-se que há uma dispersão muito grande dos valores estimados em relação aos valores determinados diretamente. Observam-se tendências de superestimativas e subestimativas da erodibilidade, sendo que alguns modelos, inclusive, resultam em 
TABELA 2. Distribuição do tamanho de partículas e agregados dos solos estudados¹.

\begin{tabular}{|c|c|c|c|c|c|c|c|c|c|c|c|c|c|c|}
\hline \multirow{2}{*}{$\begin{array}{c}\text { Solo } \\
\left(n^{\circ}\right)\end{array}$} & \multicolumn{7}{|c|}{ Dispersão $\mathrm{NaOH} 0,1 \mathrm{~mol} \mathrm{~L}^{-1}$} & \multicolumn{7}{|c|}{ Dispersão água } \\
\hline & AMG & AG & $\mathrm{AM}$ & $\mathrm{AF}$ & AMF & Silte & Argila & AMG & AG & $\mathrm{AM}$ & $\mathrm{AF}$ & AMF & Silte & Argila \\
\hline & & & & & & & $\left(\mathrm{g} \mathrm{k}_{\mathrm{k}}\right.$ & & & & & & & --- \\
\hline 1 & 0 & 10 & 30 & 10 & 120 & 160 & 670 & 0 & 10 & 80 & 170 & 70 & 410 & 260 \\
\hline 2 & 0 & 10 & 50 & 320 & 90 & 60 & 470 & 0 & 20 & 80 & 370 & 140 & 270 & 120 \\
\hline 3 & 0 & 10 & 10 & 20 & 20 & 150 & 790 & 0 & 30 & 50 & 100 & 60 & 430 & 330 \\
\hline 4 & 10 & 40 & 80 & 120 & 40 & 80 & 630 & 20 & 90 & 120 & 190 & 80 & 240 & 260 \\
\hline 5 & 0 & 0 & 10 & 30 & 20 & 80 & 860 & 10 & 70 & 80 & 140 & 70 & 629 & 1 \\
\hline 6 & 0 & 0 & 150 & 220 & 490 & 1 & 139 & 0 & 0 & 130 & 670 & 100 & 60 & 40 \\
\hline 7 & 2 & 11 & 182 & 397 & 85 & 47 & 279 & 0 & 8 & 155 & 442 & 141 & 155 & 99 \\
\hline 8 & 10 & 50 & 80 & 120 & 40 & 100 & 600 & 20 & 110 & 140 & 180 & 70 & 240 & 240 \\
\hline 9 & 10 & 40 & 70 & 80 & 40 & 110 & 650 & 10 & 60 & 90 & 160 & 80 & 380 & 220 \\
\hline 10 & 0 & 20 & 140 & 130 & 370 & 1 & 339 & 10 & 30 & 180 & 10 & 480 & 210 & 80 \\
\hline 11 & 10 & 30 & 40 & 0 & 100 & 100 & 720 & 20 & 100 & 130 & 60 & 230 & 210 & 250 \\
\hline 12 & 10 & 30 & 30 & 60 & 40 & 110 & 720 & 20 & 100 & 170 & 180 & 80 & 260 & 190 \\
\hline 13 & 10 & 20 & 30 & 10 & 50 & 30 & 850 & 10 & 60 & 110 & 260 & 90 & 280 & 190 \\
\hline 14 & 0 & 10 & 40 & 190 & 120 & 100 & 540 & 0 & 10 & 60 & 260 & 190 & 310 & 170 \\
\hline 15 & 0 & 10 & 60 & 210 & 90 & 110 & 520 & 0 & 20 & 110 & 360 & 110 & 280 & 120 \\
\hline 16 & 30 & 150 & 180 & 160 & 30 & 10 & 440 & 30 & 160 & 210 & 210 & 60 & 220 & 110 \\
\hline 17 & 20 & 80 & 180 & 60 & 460 & 50 & 150 & 30 & 110 & 180 & 470 & 90 & 100 & 20 \\
\hline 18 & 22 & 96 & 72 & 44 & 7 & 114 & 645 & 35 & 141 & 157 & 192 & 70 & 170 & 235 \\
\hline 19 & 0 & 30 & 220 & 300 & 50 & 40 & 360 & 10 & 30 & 230 & 330 & 90 & 150 & 160 \\
\hline
\end{tabular}

1 AMG: areia muito grossa (2,0 a $1,0 \mathrm{~mm})$; AG: areia grossa $(1,0$ a $0,5 \mathrm{~mm})$; AM: areia média $(0,5$ a $0,25 \mathrm{~mm})$; AF: areia fina $(0,25$ a $0,105 \mathrm{~mm})$; AMF: areia muito fina $(0,105$ a $0,053 \mathrm{~mm})$

TABELA 3. Parâmetros físicos e relações utilizadas na determinação pelos métodos indiretos da erodibilidade dos solos estudados ${ }^{1}$.

\begin{tabular}{|c|c|c|c|c|c|c|c|c|c|c|c|}
\hline \multirow{2}{*}{$\begin{array}{c}\text { Solo } \\
\left(\mathrm{n}^{\circ}\right)\end{array}$} & \multicolumn{2}{|c|}{ Classes } & $M$ & $\mathrm{Ma}$ & $\mathrm{Mm}$ & MH & \multirow{2}{*}{$\begin{array}{l}\text { DMP } \\
(\mathrm{mm})\end{array}$} & \multirow{2}{*}{ MQ } & \multirow{2}{*}{ EU } & \multirow{2}{*}{$\mathrm{CA}$} & \multirow[t]{2}{*}{$\mathrm{C}$} \\
\hline & $\mathrm{S}$ & $\mathrm{P}$ & ------------ & ------------ & $\left.g^{-2}\right)--$ & ------------- & & & & & \\
\hline 1 & 2 & 3 & 16.500 & 355.200 & 27.200 & 14.000 & 0,034 & 81 & 219 & 0 & 10 \\
\hline 2 & 2 & 3 & 201.400 & 360.800 & 22.800 & 57.000 & 0,091 & 53 & 191 & 0 & 10 \\
\hline 3 & 3 & 3 & 8.400 & 328.300 & 25.500 & 6.800 & 0,021 & 72 & 277 & 0 & 10 \\
\hline 4 & 2 & 1 & 92.500 & 236.800 & 16.000 & 30.000 & 0,102 & 40 & 224 & 0 & 50 \\
\hline 5 & 2 & 3 & 5.600 & 698.301 & 8.800 & 4.000 & 0,013 & 77 & 272 & 0 & 0 \\
\hline 6 & 3 & 2 & 318.200 & 153.600 & 221 & 181.670 & 0,132 & 314 & 33 & 0 & 0 \\
\hline 7 & 3 & 2 & 428.608 & 266.696 & 20.868 & 78.144 & 0,157 & 190 & 150 & 0 & 13 \\
\hline 8 & 2 & 2 & 104.000 & 235.600 & 22.000 & 36.400 & 0,110 & 32 & 194 & 0 & 60 \\
\hline 9 & 3 & 1 & 70.000 & 358.800 & 20.900 & 30.000 & 0,092 & 76 & 198 & 0 & 50 \\
\hline 10 & 3 & 1 & 191.400 & 634.800 & 131 & 107.590 & 0,118 & 77 & 112 & 0 & 20 \\
\hline 11 & 1 & 1 & 22.400 & 330.000 & 10.000 & 16.000 & 0,063 & 66 & 232 & 0 & 40 \\
\hline 12 & 3 & 3 & 36.400 & 275.400 & 18.700 & 19.500 & 0,066 & 72 & 277 & 0 & 40 \\
\hline 13 & 3 & 2 & 10.500 & 299.700 & 1.200 & 5.600 & 0,048 & 134 & 285 & 0 & 30 \\
\hline 14 & 2 & 1 & 110.400 & 415.000 & 29.000 & 52.800 & 0,068 & 26 & 201 & 0 & 10 \\
\hline 15 & 2 & 3 & 134.400 & 343.200 & 35.200 & 56.000 & 0,077 & 28 & 187 & 0 & 10 \\
\hline 16 & 2 & 1 & 291.200 & 249.200 & 1.700 & 20.800 & 0,256 & 21 & 156 & 0 & 180 \\
\hline 17 & 2 & 2 & 289.000 & 186.200 & 5.500 & 173.400 & 0,204 & 33 & 68 & 0 & 100 \\
\hline 18 & 2 & 3 & 83.070 & 183.600 & 18.012 & 28.314 & 0,144 & 156 & 398 & 0 & 118 \\
\hline 19 & 2 & 3 & 352.000 & 201.600 & 13.600 & 49.500 & 0,163 & 22 & 116 & 0 & 30 \\
\hline
\end{tabular}

1 S: estrutura; P: permeabilidade; M: soma dos teores de silte e areia muito fina multiplicados por 1000 menos o teor de argila; Ma: o mesmo significado de $\mathrm{M}$, porém a dispersão sendo feita somente com água; $\mathrm{Mm}$ : teor de silte multiplicado pela soma de silte e areia fina; $\mathrm{MH}$ : teor da fração areia maior que $0,105 \mathrm{~mm}$, multiplicado pela soma dos teores de silte e areia muito fina; DMP: diâmetro médio ponderado da fração menor que $2 \mathrm{~mm}$; MQ: índice de instabilidade; EU: equivalente de umidade; CA: teor de partículas maiores que $2,0 \mathrm{~mm}$; C: teor de partículas maiores que $0,5 \mathrm{~mm}$ correspondente à parte da fração areia mais calhaus. 
TABELA 4. Parâmetros químicos e relações utilizadas na determinação pelos métodos indiretos da erodibilidade dos solos estudados ${ }^{1}$.

\begin{tabular}{|c|c|c|c|c|c|c|c|c|c|c|c|c|}
\hline \multirow{2}{*}{$\begin{array}{c}\text { Solo } \\
\left(\mathrm{n}^{0}\right)\end{array}$} & \multicolumn{2}{|c|}{$\mathrm{SiO}_{2}$} & \multicolumn{2}{|c|}{$\mathrm{Al}_{2} \mathrm{O}_{3}$} & \multicolumn{2}{|c|}{$\mathrm{Fe}_{2} \mathrm{O}_{3}$} & \multirow[t]{2}{*}{ MO } & \multirow[t]{2}{*}{ PROD } & \multirow[t]{2}{*}{ ALA } & \multirow[t]{2}{*}{$\mathrm{V}$} & \multicolumn{2}{|c|}{$\mathrm{pH}$} \\
\hline & AS & DCB & AS & DCB & AS & DCB & & & & & $\mathrm{H}_{2} \mathrm{O}$ & $\mathrm{KCl}$ \\
\hline & -----. & -------- & - & $\left(\mathrm{g} \mathrm{kg}^{-1}\right.$ & ------- & ------- & -----. & & & $(\%)$ & & \\
\hline 1 & 199 & 8 & 182 & 21 & 210 & 82 & 26 & 1.300 & 0,272 & 34 & 4,8 & 3,8 \\
\hline 2 & 149 & 7 & 143 & 11 & 63 & 31 & 31 & 11.780 & 0,304 & 15 & 4,2 & 3,8 \\
\hline 3 & 246 & 12 & 217 & 32 & 139 & 61 & 45 & 1.800 & 0,275 & 38 & 5,1 & 4,2 \\
\hline 4 & 172 & 9 & 220 & 26 & 178 & 64 & 22 & 5.500 & 0,349 & 49 & 5,1 & 4,5 \\
\hline 5 & 253 & 12 & 270 & 31 & 268 & 89 & 14 & 560 & 0,314 & 33 & 4,7 & 4,1 \\
\hline 6 & 42 & 2 & 66 & 3 & 27 & 9 & 9 & 3.330 & 0,472 & 22 & 4,4 & 3,8 \\
\hline 7 & 95 & 4 & 125 & 18 & 52 & 25 & 9 & 5.328 & 0,448 & 46 & 5,8 & 4,5 \\
\hline 8 & 161 & 10 & 208 & 19 & 178 & 58 & 26 & 6.760 & 0,347 & 47 & 5,1 & 4,5 \\
\hline 9 & 203 & 9 & 213 & 18 & 301 & 56 & 13 & 2.600 & 0,328 & 52 & 5,4 & 4,7 \\
\hline 10 & 114 & 3 & 192 & 11 & 100 & 18 & 18 & 5.220 & 0,565 & 28 & 5,0 & 4,3 \\
\hline 11 & 159 & 8 & 270 & 31 & 125 & 35 & 32 & 2.560 & 0,375 & 16 & 5,0 & 4,3 \\
\hline 12 & 141 & 7 & 330 & 23 & 110 & 47 & 47 & 6.110 & 0,458 & 13 & 5,1 & 4,3 \\
\hline 13 & 234 & 12 & 319 & 35 & 120 & 55 & 38 & 2.660 & 0,375 & 29 & 4,6 & 4,1 \\
\hline 14 & 95 & 8 & 241 & 16 & 108 & 39 & 28 & 6.720 & 0,446 & 15 & 4,7 & 4,2 \\
\hline 15 & 150 & 6 & 187 & 17 & 88 & 31 & 42 & 11.760 & 0,360 & 23 & 4,7 & 4,2 \\
\hline 16 & 135 & 6 & 149 & 20 & 39 & 6 & 42 & 21.840 & 0,339 & 28 & 5,2 & 4,2 \\
\hline 17 & 46 & 2 & 75 & 6 & 15 & 3 & 25 & 8.500 & 0,500 & 10 & 4,9 & 4,1 \\
\hline 18 & 329 & 7 & 276 & 13 & 39 & 5 & 38 & 8.892 & 0,428 & 9 & 4,4 & 4,0 \\
\hline 19 & 124 & 5 & 135 & 12 & 33 & 6 & 15 & 8.250 & 0,375 & 35 & 5,0 & 4,2 \\
\hline
\end{tabular}

1 AS: óxidos extraídos pelo ataque sulfúrico; DCB: óxidos extraídos pelo ditionito-citrato-bicarbonato de sódio; MO (matéria orgânica): C org. x 1,72; PROD: produto do teor de matéria orgânica pela quantidade de partículas de diâmetro entre 0,1 e 2,0 mm; ALA: teor de óxidos de alumínio extraídos pelo ataque sulfúrico dividido pelo teor de argila; V: saturação por bases.

valores negativos para aquele índice. Outro aspecto geral que se constata é que os coeficientes das correlações envolvendo os índices estimados e determinados são sistematicamente baixos e não-significativos.

Na Fig. 1 são plotados, contra os valores de erodibilidade obtidos pelos métodos diretos, os valores de erodibilidade obtidos pelos modelos I, II, III, IV e V propostos por Dumas (1965), e pelo modelo VI proposto por Wischmeier et al. (1971). Com relação aos modelos de Dumas (1965), observa-se uma tendência generalizada de superestimativa dos valores da erodibilidade dos Latossolos brasileiros. Segundo aquele autor, os principais fatores envolvidos no processo erosivo do solo são a sua umidade inicial, a estabilidade estrutural e a proteção superficial, no caso, representada pela intervenção de partículas de areias (diâmetro entre 0,5 e 2,0 mm) e calhaus (diâmetro entre 2,0 e 20,0 cm), ao impacto das gotas de chuva. De acordo com Roose \& Sarrailh (1989), o parâmetro relacionado à presença de partículas maiores que $0,5 \mathrm{~mm}$ na superfície do terreno é responsável por $69 \%$ a $100 \%$ do valor de erodibilidade para aqueles modelos. Assim, pode-se atribuir a tendência de superestimativa da erodibilidade pelos modelos de Dumas (1965), principalmente à ausência de calhaus na superfície dos Latossolos brasileiros estudados.

Os modelos VI (Fig. 1), VII, IX, X, XI e XII (Fig. 2), XIV e XVII (Fig. 3), XX, XXII e XXIII (Fig. 4) tenderam a subestimar a erodibilidade, tendo sido observados valores negativos; comportamento semelhante foi observado por Oliveira \& Bahia (1984) e Silva et al. (1994b). Para o modelo VI (Fig. 1), os baixos valores apresentados em relação ao método direto foram creditados por Henklain \& Freire (1983); Angulo et al. (1985); Lima et al. (1990) e Silva et al. (1994a) às diferenças granulométricas existentes entre os solos estudados e os utilizados para a geração do modelo. Observa-se que os baixos teores de silte (dispersão com $\mathrm{NaOH} 0,1 \mathrm{~mol} \mathrm{~L}^{-1}$ ) resultaram em valores baixos do parâmetro $\mathrm{M}$ (soma dos teores de silte e areia muito fina multiplicados por 1.000 menos o teor de argila) (Tabela 3). Com exceção de três Latossolos de textura média, os demais solos apresentaram valores bem inferiores aos valores utiliza- 

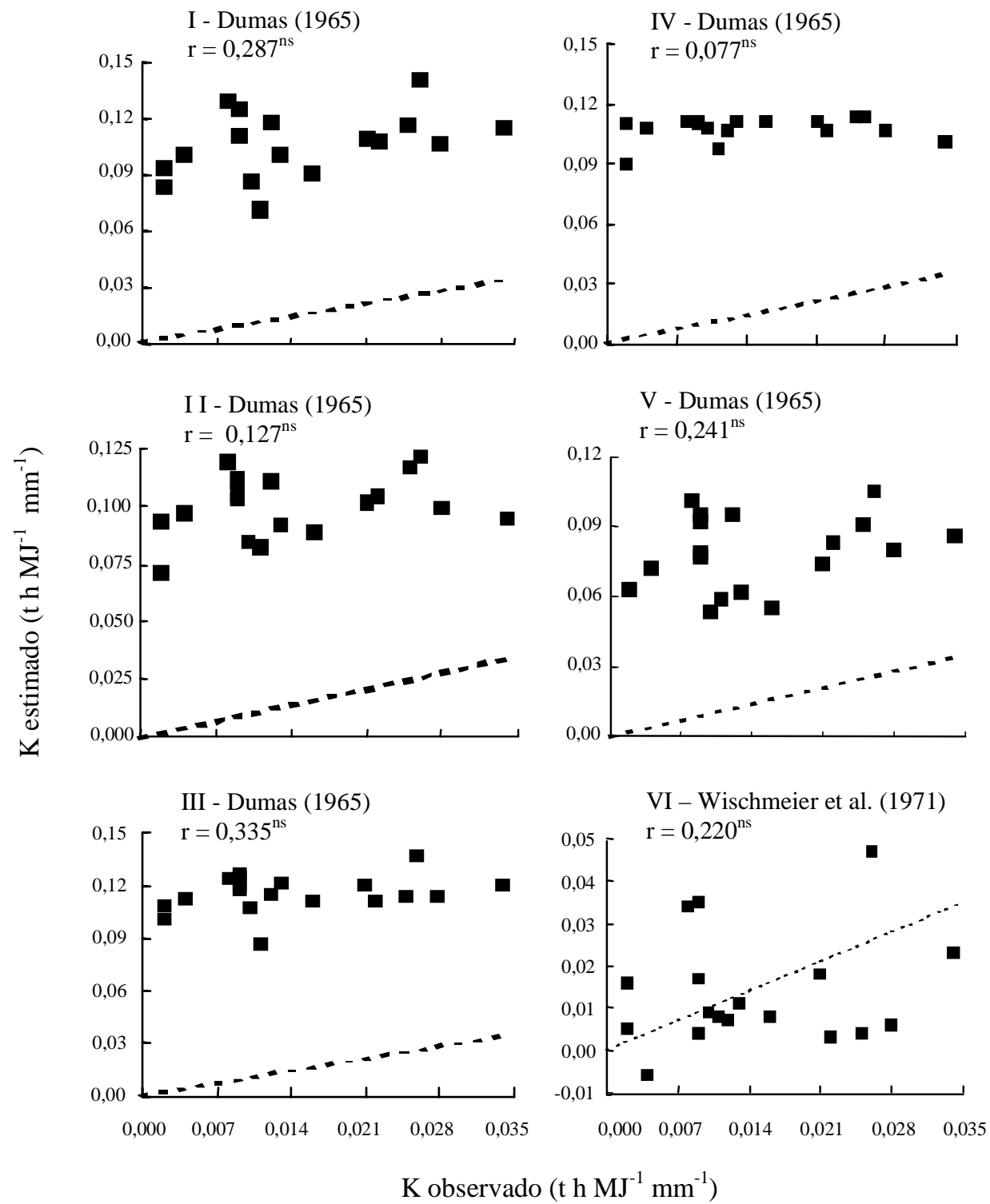

FIG. 1. Relação entre a erodibilidade (fator K) estimada pelos métodos I, II, III, IV, V e VI e $o$ fator $\mathrm{K}$ observado. $O$ traço pontilhado representa a linha 1:1 ("ss: não-significativo).

dos na geração do modelo (menores que $300.000 \mathrm{~g}^{2} \mathrm{~kg}^{-2}$ ). Estes aspectos corroboram as observações de Denardin (1990) e Silva et al. (1994a).

O modelo VII (Fig. 2), proposto por Roth et al. (1974), revelou-se, também, inadequado para estimar a erodibilidade. Estes resultados denotam a inaplicabilidade deste modelo para a estimativa da erodibilidade de Latossolos brasileiros, resultados que estão de acordo com os estudos de Denardin (1990).

Os modelos IX e X (Fig. 2) de El-Swaify \& Dangler (1977) forneceram valores que não se correlacionaram 


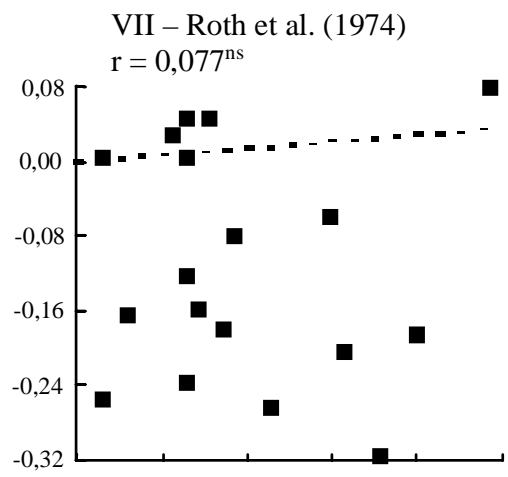

VIII - Lombardi Neto \& Bertoni (1975)

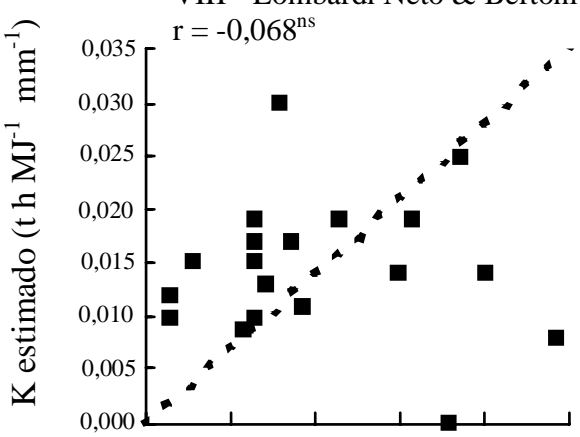

IX - El-Swaify \& Dangler (1977)

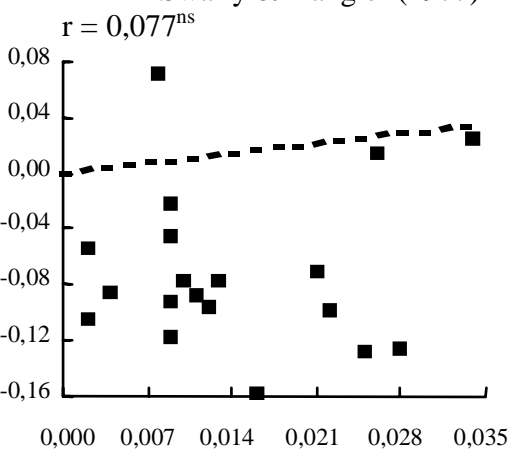

X - El-Swaify \& Dangler (1977) $\mathrm{r}=0,241^{\mathrm{ns}}$
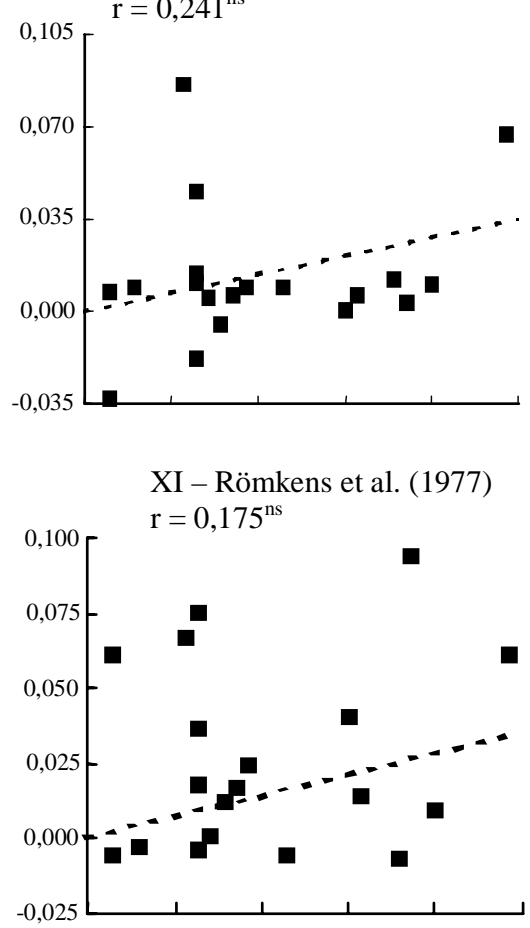

XII - Römkens et al. (1977) $\mathrm{r}=0,037^{\mathrm{ns}}$

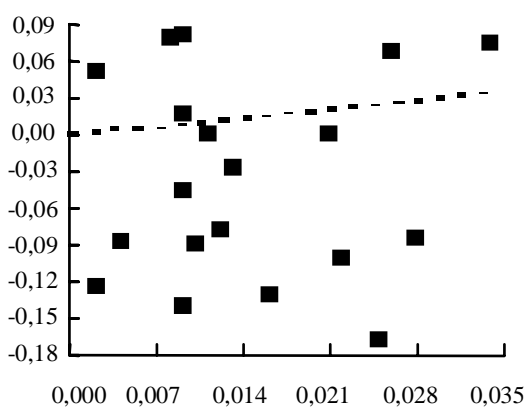

K observado ( $\mathrm{h} \mathrm{MJ}^{-1} \mathrm{~mm}^{-1}$ )

FIG. 2. Relação entre a erodibilidade (fator K) estimada pelos métodos VII, VIII, IX, X, XI e XII e o fator Kobservado. $O$ traço pontilhado representa a linha 1:1 ("ns: não-significativo).

com a erodibilidade observada. Apesar de os modelos considerarem o parâmetro índice de estabilidade (Tabela 3), tido como importante no estudo da erosão hídrica, o modelo subestima em demasia o valor da erodibilidade dos Latossolos, apresentando valores negativos para a maioria dos solos estudados, notadamente para o modelo IX. A variável MQ (índice de instabilidade) (Tabela 3) foi considerada de reprodução difícil, e a variável V (saturação por bases) (Tabela 4) apresenta diferenças metodológicas em relação aos métodos utilizados no Brasil, aspectos, estes, que talvez tenham contribuído para a impreci- 


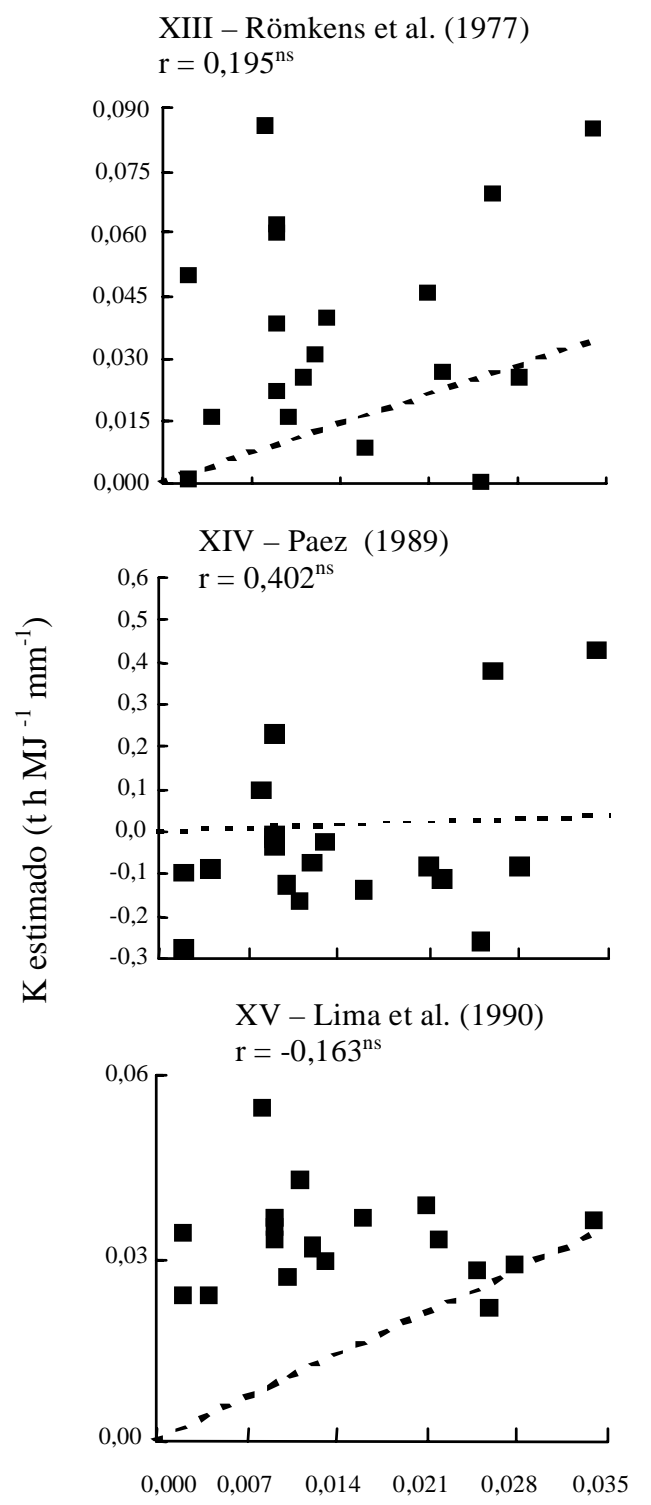

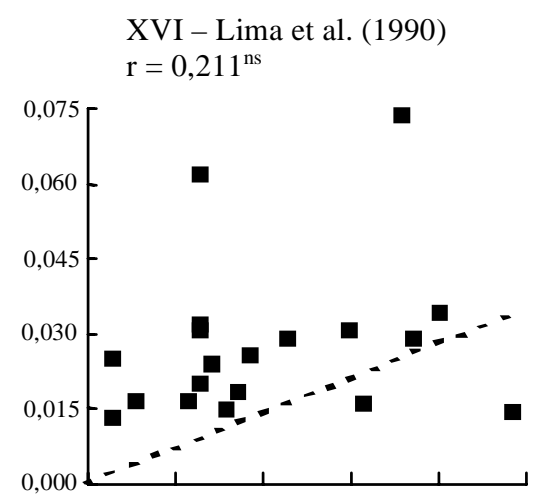
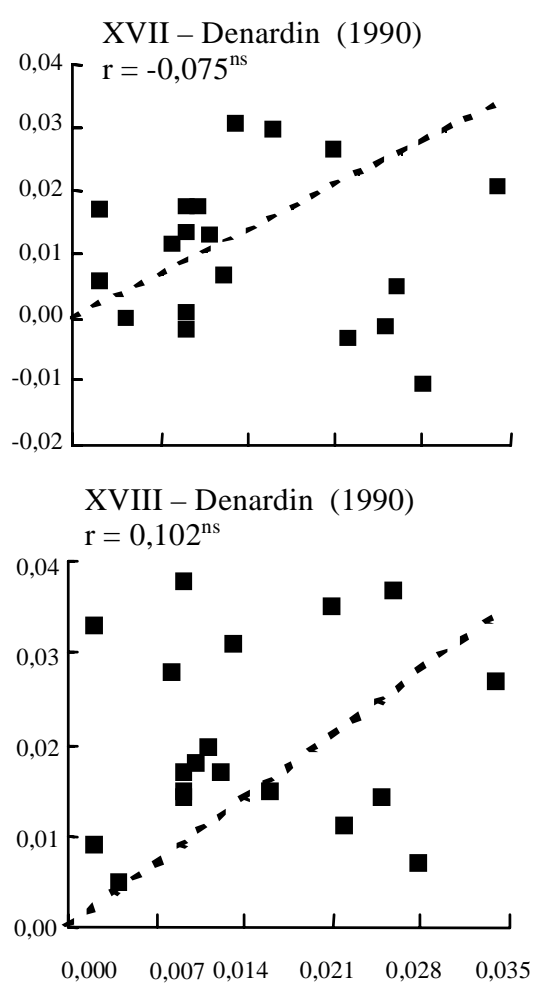

K observado ( $\left.\mathrm{t} \mathrm{h} \mathrm{MJ}^{-1} \mathrm{~mm}^{-1}\right)$

FIG. 3. Relação entre a erodibilidade (fator K) estimada pelos métodos XIII, XIV, XV, XVI, XVII e XVIII e o fator Kobservado. O traço pontilhado representa a linha 1:1 ("ss: nãosignificativo).

são do método. Observações semelhantes foram constatadas por Marques et al. (1997). Dos 12 solos envolvidos na obtenção do modelo de El-Swaify \& Dangler (1977), todos da região tropical, apenas três são Oxissolos que podem ser considerados seme- lhantes aos solos deste trabalho; os demais possuem atributos bastante contrastantes, com conseqüente comportamento diferenciado frente à erosão.

O comportamento dos modelos desenvolvidos por Römkens et al. (1977) pode ser observado nas 
XIX - Roloff \& Denardin (1994)

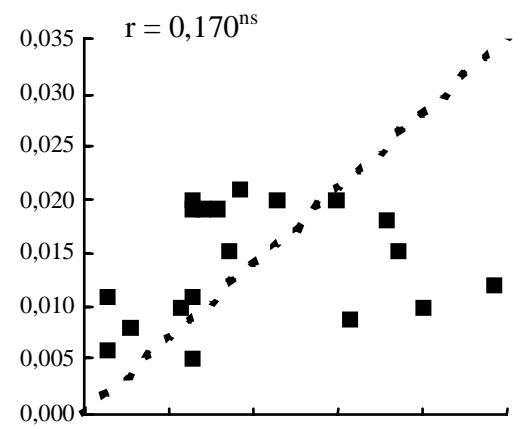

XX - Roloff \& Denardin (1994)

טִ

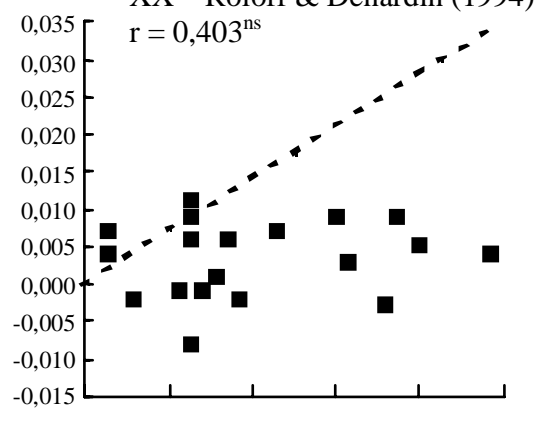

XXI - Roloff \& Denardin (1994)

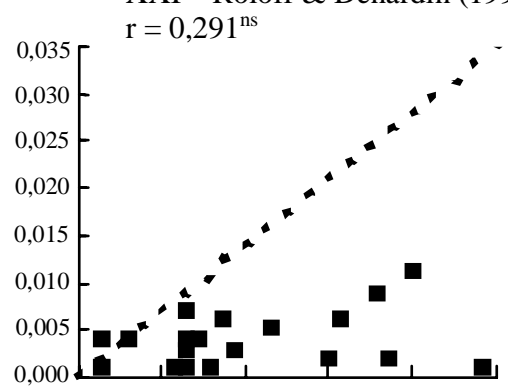

$\begin{array}{llllll}0,000 & 0,007 & 0,014 & 0,021 & 0,028 & 0,035\end{array}$
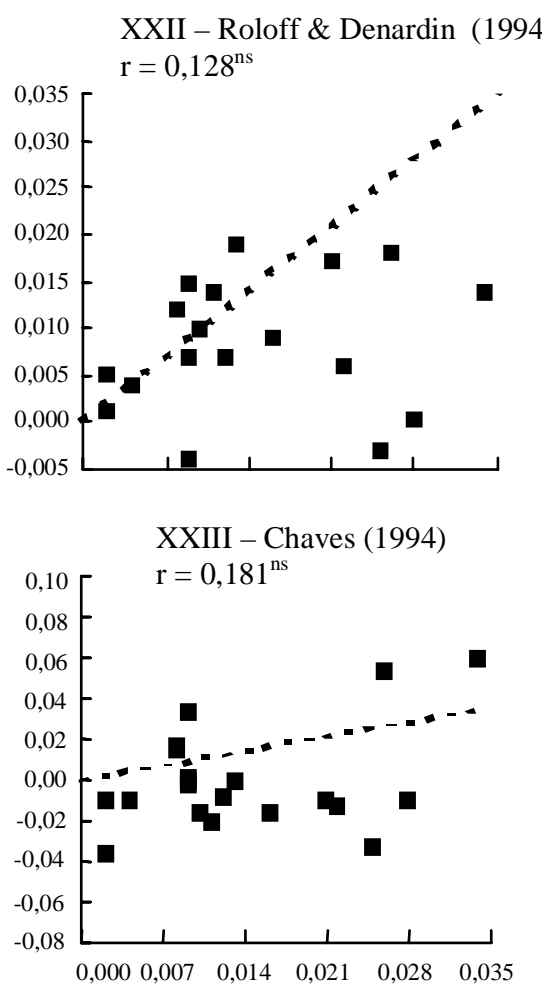

K observado $\left(\mathrm{t} \mathrm{h} \mathrm{MJ} \mathrm{Mm}^{-1}\right)$

$\mathrm{K}$ observado ( $\mathrm{t} \mathrm{h} \mathrm{MJ}^{-1} \mathrm{~mm}^{-1}$ )

FIG. 4. Relação entre a erodibilidade (fator K) estimada pelos métodos XIX, XX, XXI, XXII e XXIII e o fator K observado. O traço pontilhado representa a linha 1:1 (ns: nãosignificativo).

Figs. 2 e 3 . Estes modelos apresentaram grande dispersão dos dados e, com exceção do modelo XIII (Fig.3), valores negativos, notadamente o modelo XII (Fig. 2) no tocante à maioria dos solos estudados, confirmando a inadequação destes modelos para
Latossolos brasileiros. Römkens et al. (1977), utilizando a mesma série de solos de Wischmeier et al. (1971), modificaram tal modelo mediante a inclusão dos teores de $\mathrm{Fe}_{2} \mathrm{O}_{3}$ e $\mathrm{Al}_{2} \mathrm{O}_{3}$ extraídos pelo DCB (ditionito-citrato-bicarbonato de sódio), devido ao 
efeito agregante que estes teriam no solo, porém estes modelos foram gerados para subsolos com altos teores de silte, os quais diferem substancialmente dos solos aqui utilizados.

Na Fig. 3, observa-se o comportamento do método XIV proposto por Paez (1989). Este modelo foi desenvolvido para solos agrícolas da Venezuela. Apesar de apresentar o segundo maior coeficiente de correlação, os valores de erodibilidade foram muito distorcidos, e apresentaram valores negativos. Um dos motivos que levou a estes resultados, a exemplo de outros modelos, pode estar relacionado aos grupamentos de solos envolvidos no modelo, que, em sua grande maioria, eram Alfissolos e Ultissolos, estando presente apenas um Oxissolo.

Nas Figs. 1 a 3 são apresentados os gráficos de dispersão dos valores de erodibilidade observados em relação aos estimados pelos métodos VI, VIII, XV e XVI, propostos, respectivamente, por Wischmeier et al. (1971), Lombardi Neto \& Bertoni (1975) e Lima et al. (1990). Observa-se que nenhum dos métodos indiretos citados apresentou correlação significativa com os métodos diretos. Os modelos XV e XVI propostos por Lima et al. (1990) apresentaram valores de erodibilidade superiores aos valores estimados pelos modelos originais VI e VIII propostos, respectivamente, por Wischmeier et al. (1971) e Lombardi Neto \& Bertoni (1975). Resultados semelhantes foram encontrados por Silva et al. (1994a), pelo estudo com Latossolos da região dos cerrados e por Silva et al. (1994b) estudando solos da região de Manaus (AM).

A estimativa da erodibilidade pelos métodos XV e XVI (Lima et al. 1990) (Fig. 3) possibilitou um aumento substancial da erodibilidade em relação aos métodos originais, ou seja, VI (Wischmeier et al., 1971) e VIII (Lombardi Neto \& Bertoni, 1975). Uma explicação para isso é que a estimativa da erodibilidade fundamenta-se no fato de que, em Latossolos, as partículas de argila floculadas apresentam comportamento semelhante ao do silte e da areia muito fina (Lima et al., 1990), afetando o comportamento desses solos em face do processo erosivo. Quando se utilizou água como dispersante, as frações correspondentes ao silte mais areia muito fina aumentaram, possibilitando uma elevação do parâmetro M(Lima et al., 1990; Silva et al., 1994a, 1994b).
Por outro lado, Marques et al. (1997), trabalhando com solos com B textural, não constataram elevação do parâmetro $\mathrm{M}$, e poucos solos apresentaram Ma (mesmo significado de $\mathrm{M}$, porém a dispersão sendo feita com água) acima de $300.000 \mathrm{~g}^{2} \mathrm{~kg}^{-2}$ (Tabela 3). Tal comportamento é atribuído ao baixo índice de floculação daqueles solos. Contudo, apesar da elevação da erodibilidade, não foi também observada a adequação destes modelos, o que confirma observações de Silva et al. (1994a) no tocante a Latossolos sob cerrado. Entretanto, verificou-se certa aproximação entre os valores de erodibilidade observados e estimados no modelo XVI (Fig. 3). Estes resultados confirmam observações de Marques et al. (1997), os quais encontraram uma boa aproximação entre a erodibilidade observada e a estimada pelo modelo XVI no que se refere a solos que apresentavam a relação Ki igual a 1,97 $\pm 0,13$, ao passo que nos demais solos esta relação estava em torno de 2,28 $\pm 0,26$. Neste estudo, a dispersão dos dados foi bem inferior à encontrada por Marques et al. (1997), e todos os solos apresentaram a relação $\mathrm{Ki}$ inferior a 2,03, o que está de acordo com as pressuposições de Marques et al. (1997).

A Fig. 3 refere-se aos modelos XVII e XVIII propostos por Denardin (1990). Na obtenção destes modelos, foram utilizados solos do Brasil e solos do Brasil e EUA, sendo que dos 19 solos aqui estudados, 10 foram utilizados para o desenvolvimento destes modelos. Mas não foram adequados para a estimativa da erodibilidade. Resultados semelhantes foram encontrados por Silva et al. (1994b) e Marques et al. (1997). O modelo XVIII apresentou uma dispersão dos valores inferior à do modelo XVII, porém apresentou valores negativos.

Na Fig. 4, observa-se o comportamento dos modelos XIX, XX, XXI e XXII, propostos por Roloff \& Denardin (1994), citados por Silva (1997). Objetivando estimar a erodibilidade para os principais solos ocorrentes no Estado do Paraná, Roloff \& Denardin (1994), citados por Silva (1997), retrabalharam os dados de Denardin (1990), visando desenvolver modelos que contemplavam atributos incluídos em levantamentos de solos do Estado. Segundo esses autores, o uso da variável $\mathrm{P}$ (permeabilidade) (Tabela 3) causa dúvidas na inferência dos seus códigos, em razão da falta de 
critérios precisos. A definição da classe de permeabilidade adotada por Wischmeier et al. (1971) é muito provisória e deve ser inferida com base na experiência do observador. A fragilidade dos critérios e a dependência da experiência do observador tornam a probabilidade de erro muito grande, uma vez que são citadas apenas seis classes. O refinamento deste parâmetro é importante, notadamente no que diz respeito aos Latossolos.

Numa tentativa de melhorar a predição da erodibilidade, Roloff \& Denardin (1994), citados por Silva (1997), propuseram mais três modelos, nos quais se exclui a variável $P$. Segundo este critério, o modelo XX torna-se o melhor modelo, apresentando o maior coeficiente de correlação entre todos os modelos estudados; mas, mesmo assim, neste estudo, o uso deste modelo não apresentou bom desempenho, pois apresentou valores negativos. $\mathrm{O}$ modelo XXI foi desenvolvido especificamente para Latossolos e Areias Quartzosas, mas este também não foi adequado para a estimativa da erodibilidade, pois apresentou uma tendência de subestimar a erodibilidade dos solos estudados, possivelmente pelo fato de estarem incluídos neste modelo solos predominantemente de textura média e arenosa, a exemplo dos solos de Paranavaí e Bela Vista do Paraíso. O modelo XXII foi desenvolvido para solos Podzólicos e Terra Roxa Estruturada, porém apresentou uma grande dispersão dos pontos e valores negativos, o que mostra a sua inadequação.

O modelo XXIII (Fig. 4), desenvolvido por Chaves (1994), foi obtido através de um estudo semelhante ao desenvolvido por Roloff \& Denardin (1994), citados por Silva (1997), numa tentativa de regionalização do modelo para a região do Vale do São Francisco a partir dos dados compilados por Denardin (1990). Chaves (1994) obteve uma relação distinta, usando dados de 19 solos com atributos semelhantes aos principais solos ocorrentes na região em questão. A exemplo dos outros resultados, este modelo também forneceu valores que não se correlacionaram com a erodibilidade observada.

\section{CONCLUSÃo}

Nenhum dos 23 métodos testados mostrou-se recomendável para a estimativa da erodibilidade para o conjunto dos Latossolos estudados, sendo necessário o desenvolvimento de modelos específicos para este grupamento de solos.

\section{AGRADECIMENTOS}

Aos seguintes pesquisadores e professores por seu espírito colaborativo no envio das amostras e informações de solos das mais distantes localidades do Brasil: José Eloir Denardin (Embrapa-CNPT), Rivaldo Dehen (COTRIJUI), Wenceslau Geraldes Teixeira (Embrapa-CPAA), Tarcísio Ewerton Rodrigues (Embrapa-CPATU), Dimas Vital Siqueira Resk (Embrapa-CPAC), Leo Dark da Costa e Pedro Luiz de Freitas (Embrapa-CNPS), Philippe Blancaneaux (ORSTOM), Gustavo Ribas Curcio (Embrapa-CNPF), Luiz Carlos Hernani (EmbrapaCPAO), Felipe Marum e Celso de Castro Filho (IAPAR), Vicente de Paula Pereira e Marcílio Vieira Martins (UNESP), Milton da Veiga (EPAGRI), Iêde Brito Chaves e Ivandro França Silva (UFPB), José Ronaldo Coelho Silva (UFC), Derli Prudente Santana e Ramon Costa Alvarenga (Embrapa-CNPMS), Francisco Lombardi Neto e Sônia Carmela Falci Dechen (IAC-SCS).

\section{REFERÊNCIAS}

ANGULO, R.J. Relações entre a erodibilidade e algumas propriedades de solos brasileiros. Curitiba : URPR, 1983. 154p. Dissertação de Mestrado.

ANGULO, R.J.; ROLOFF, G.; SOUZA, M.L.P. Aplicabilidade do nomograma de Wischmeier et al. (1971) para determinação da erodibilidade de solos brasileiros. Revista do Setor de Ciências Agrárias, Curitiba, v.7, n.1/2, p.145-153, 1985.

BERTONI, J.; LOMBARDI NETO, F. Conservação do solo. Piracicaba : Ícone, 1985. 392p.

CAMARGO, O.A.; MONIZ, A.C.; JORGE, J.A.; VALADARES, J.M.A.S. Métodos de análise química, mineralógica e física de solos do Instituto Agronômico de Campinas. Campinas : IAC, 1986. 94p. (Boletim Técnico, 106).

CHAVES, H.M.L. Aplicacion de los métodos de predicción de riesgo de erosion potencial y actual en la 
planificación de suelos y águas a nivel de microcuencas. In: FAO (Roma, Itália). Erosion de suelos en America Latina. Santiago, 1994. p.187190.

DAY, P.R. Particle fractionation and particle-size analysis. In: BLACK, C.A. (Ed.). Methods of soil analysis Madison : American Society of Agronomy, 1965 v.1, p.545-566.

DEDECEK, R.A.; RESK, D.V.S.; FREITAS JÚNIOR, E Perdas de solo, água e nutrientes por erosão em Latossolo Vermelho-Escuro em diferentes cultivos sob chuva natural. Revista Brasileira de Ciência do Solo, Campinas, v.10, n.3, p.265-272, set./dez. 1986.

DENARDIN, J.E. Erodibilidade de solo estimada por meio de parâmetros físicos e químicos. Piracicaba : USP-Esalq, 1990. 81p. Tese de Doutorado.

DUMAS, J. Relation entre l'érodibilité des sols et leurs caractéristiques analytiques. Cahiers Orstom Série Pédologie, Bondy, v.3, n.4, p.307-333, 1965

EL-SWAIFY, S.A.; DANGLER, E.W. Erodibilities of selected tropical soils in relation to structural and hydrologic parameters. In: NATIONAL CONFERENCE ON SOIL EROSION, 30., 1976, West Lafayette. Proceedings. Ankeny : Soil and Water Conservation Society, 1977. p.105-110.

EL-SWAIFY, S.A.; DANGLER, E.W. Rainfall erosion in the tropics: a state-of-the-art. In: KRAL, D.M. (Ed.). Determinants of soil loss tolerance. Madison : American Society of Agronomy, 1992. p.1-25. (ASA Special Publication, 45).

EMBRAPA. Serviço Nacional de Levantamento e Conservação de Solos (Rio de Janeiro, RJ). Manual de métodos de análise de solos. Rio de Janeiro, 1979. não paginado.

FERNANDEZ MEDINA, B.; OLIVEIRA JÚNIOR, R.C A aplicabilidade de alguns índices erosivos em Latossolo Amarelo de Manaus (AM). Revista Brasileira de Ciência do Solo, Campinas, v.11, n.1, p.67-70, jan./abr. 1987.

FOSTER, G.R.; McCOOL, K.G.; MOLDENHAUER, W.C. Conversion of the universal soil loss equation to SI metric units. Journal of Soil and Water
Conservation, Ankeny, v.36, n.6, p.355-359, Nov./ Dec. 1981

HENKLAIN, J.C.; FREIRE, O. Avaliação do método nomográfico para determinação da erodibilidade de Latossolos do Estado do Paraná. Revista Brasileira de Ciência do Solo, Campinas, v.7, n.2, p.191195, maio/ago. 1983

HERNANI, L.C.; SALTON, J.C.; FABRÍCIO, A.C.; DEDECEK, R.; ALVES JÚNIOR, M. Perdas por erosão e rendimentos de soja e de trigo em diferentes sistemas de preparo de um Latossolo R oxo de Dourados (MS). Revista Brasileira de Ciência do Solo, Campinas, v.21, n.4, p.667-676, out./dez. 1997.

KEMPER, W.D.; ROSENAU, R.C. Aggregate stability and size distribution. In: KLUTE, A. (Ed.). Methods of soil analysis. Madison : American Society of Agronomy, 1986. v.1, p.425-442.

LAL, R. Erodibility and erosivity. In: LAL, R. (Ed.). Soil erosion research methods. Ankeny : Soil and Water Conservation Society, 1988. p.141-160.

LIMA, J.M.; CURI, N.; RESENDE, M.; SANTANA, D.P. Dispersão do material de solo em água para avaliação indireta da erodibilidade em Latossolos. Revista Brasileira de Ciência do Solo, Campinas, v.14, n.1, p.85-90, jan./abr. 1990.

LOMBARDI NETO, F.; BERTONI, J. Erodibilidade de solos paulistas. Campinas : Instituto Agronômico, 1975. 12p. (Boletim Técnico, 27).

McKEAGUE, J.A. Manual on soil sampling and methods of analysis. Ottawa : Canadian Soil Science Society, 1978. 212p.

MARQUES, J.J.G.S.M.; CURI, N.; FERREIRA, M.M.; LIMA, J.M.; SILVA, M.L.N.; SÁ, M.A.C. de. Adequação de métodos indiretos para estimativa da erodibilidade de solos com horizonte B textural no Brasil. Revista Brasileira de Ciência do Solo, Campinas, v.21, n.3, p.447-456, jul./set. 1997.

MARTINS FILHO, M.V.; PEREIRA, V.P. Influência da compactação do solo nas perdas por erosão e na sua erodibilidade. Ciência Agronômica, Jaboticabal, v.8, n.1, p.39-45, jan./fev. 1993.

MEHRA, O.P.; JACKSON, M.L. Iron oxide removal from soils and clays by a dithionite-citrate system buffered with sodium bicarbonate. Clays and Clay Minerals, Evergreen, v.3, p.317-327, 1960.

Pesq. agropec. bras., Brasília, v.35, n.6, p.1207-1220, jun. 2000 
MIDDLETON, H.E. Properties of soils which influence soil erosion. Washington : USDA, 1930. 16p (Technical Bulletin, 178).

MONDARDO, A.; JUCKSCH, I.; VIEIRA, M.J.; FARIAS, G.S. de; HENKLAIN, J.C.; RUFINO, R.L. Erodibilidade do Latossolo Roxo distrófico com $8 \%$ de declive, usando simulador de chuva. Londrina : IAPAR, 1978. não paginado.

OLIVEIRA, V.H.; BAHIA, V.G. Erodibilidade de seis solos do município de Lavras, MG, usando o nomograma. Pesquisa Agropecuária Brasileira, Brasília, v.19, n.9, p.1157-1162, set. 1984.

OLIVEIRA, M.; CURI, N.; FREIRE, J.C. Influência do cultivo na agregação de um Podzólico VermelhoAmarelo textura média/argilosa da região de Lavras (MG). Revista Brasileira de Ciência do Solo, Campinas, v.7, n.3, p.317-322, set./dez. 1983.

PAEZ, M. Evaluación de la erodibilidad y eficiencia de índices de erodibilidad en suelos agrícolas de Venezuela. Maracay: Universidad Central de Venezuela, 1989. 146p. Tesis Doctoral.

RÖMKENS, M.J.M.; ROTH, C.B.; NELSON, D.W Erodibility of selected clay subsoils in relation to physical and chemical properties. Soil Science Society of America. Journal, Madison, v.41, n.5, p.954-960, Sept./Oct. 1977.

ROOSE, E.; SARRAILH, J.M. Erodibilité de quelques sols tropicaux vingt années de mesure en parcelles d'érosion sous pluies naturelles. Cahiers Orstom Série Pédologie, Bondy, v.25, p.7-30, 1989

ROTH, C.B.; NELSON, D.W.; RÖMKENS, M.J.M. Prediction of subsoil erodibility using chemical, mineralogical and physical parameters. Washington : United States Environmental Protection Agency, 1974. $111 \mathrm{p}$

SILVA, I.F.; ANDRADE, A.P.; CAMPOS FILHO, O.R Erodibilidade de seis solos do semi-árido paraibano obtida com chuva simulada e método nomográfico. Revista Brasileira de Ciência do Solo, Campinas, v.10, n.3, p.283-287, set./dez. 1986.

SILVA, M.L.N. Erosividade da chuva e proposição de modelos para estimar a erodibilidade de Latossolos brasileiros. Lavras : UFLA, 1997. 154p. Tese de Doutorado.
SILVA, M.L.N.; CURI, N.; OLIVEIRA, M.S.; FERREIRA, M.M.; LOMBARDI NETO, F. Comparação de métodos direto e indiretos para determinação da erodibilidade em Latossolos sob cerrado. Pesquisa Agropecuária Brasileira, Brasília, v.29, n.11, p.1751-1761, nov. 1994a

SILVA, M.L.N.; FREITAS, P.L.; BLANCANEUAX, P.; CURI, N.; LIMA, J.M. Relação entre parâmetros da chuva e perdas de solo e determinação da erodibilidade de um Latossolo Vermelho-Escuro em Goiânia (GO) Revista Brasileira de Ciência do Solo, Campinas, v.21, n.1, p.131-137, jan./mar. 1997.

SILVA, M.L.N; LIMA, H.N.; CURI, N. Índices de erodibilidade de solos da região de Manaus-AM determinação indireta, comparação e predição de perdas. Revista da Universidade do Amazonas: Série Ciências Agrárias, Manaus, v.3, p.69-81, jul./ dez. 1994b.

TÁVORA, M.R.P.; SILVA, J.R.C.; MOREIRA, E.G.S Erodibilidade de dois solos da região de Ibiapaba, Estado do Ceará. Revista Brasileira de Ciência do Solo, Campinas, v.9, n.1, p.59-62, jan./abr. 1985.

WEAVER, R.M.; SYERS, J.K.; JACKSON, M.L Determination of silica in citrate-bicarbonatedithionite extracts of soils. Soil Science Society of America. Proceedings, Madison, v.32, n.5, p.497501, Sept./Oct. 1968

WISCHMEIER, W.H.; JOHNSON, C.B.; CROSS, B.V.A soil erodibility nomograph for farmland and construction sites. Journal of Soil and Water Conservation, Ankeny, v.26, n.5, p.189-193, Sept./ Oct. 1971

WISCHMEIER, W.H.; MANNERING, J.V. Relation of soil properties to its erodibility. Soil Science Society of America. Proceedings, Madison, v.33, n.1, p.131-137, Jan./Feb. 1969

WISCHMEIER, W.H.; SMITH, D.D. Predicting rainfall erosion losses: a guide to conservation planning Washington: USDA, 1978. 58p. (Agriculture Handbook, 537).

YOUNG, R.A.; MUTCHLER, C.K. Erodibility of some Minnesota soils. Journal of Soil and Water Conservation, Ankeny, v.32, n.4, p.180-182, July/Aug. 1977. 